\title{
Diagnostics of Robot Drives Based on DC Motors by Identifiability Criterion of Nonlinear Discrete Model in State Space
}

\author{
Yu. R. Nikitin, S. A. Trefilov \\ Department of Mechatronic Systems, \\ Kalashnikov Izhevsk State Technical University, Izhevsk, Russian Federation \\ E-mail: nikitin@istu.ru
}

Received: June 15, 2020

\begin{abstract}
The paper studies robot drives by the identifiability criterion based on a discrete digital control model. Criteria of observability, controllability and identifiability of drives as a function of the rank of an extended state matrix with a measurement matrix are considered, in which the relative errors of the information-measuring system are analytically taken into account. An algorithm is proposed for calculating the identifiability criterion for a nonlinear control system in a discrete linearization version. It is proposed to use identification in terms of the correspondence of the mathematical model to the results of the operation of the object. At each step, the determinant of the extended matrix is calculated, which is compared with a constant that numerically divides the space of the state matrices. Thus, the operation of the drives itself makes it possible to determine its identifiability. As a criterion for the optimality of the identification algorithm, a decision-making optimality criterion is chosen in combination with an identifiability criterion for an optimal control algorithm by the criterion of minimum quadratic form. The vector-matrix model of drives in the state space is presented taking into account the relative accuracy of measuring the state of the information-measuring subsystem of drives. It is proposed for practical problems to determine the identifiability criterion by modeling the state matrix for cases when the state matrix parameters exit the space of realizable parameters of serviceable drives. The research results obtained can be used to build diagnostic systems for robot drives.
\end{abstract}

Keywords: Diagnostics, Identification, State space, Velocity control, DC motors, Robots, Modeling

\section{INTRODUCTION}

To ensure high reliability of robot drives, an effective diagnostic system is required. For the diagnosis of robot drives, an algorithm is proposed for deciding on their identifiability based on a discrete nonlinear control model in the state space.

The method of identification in the state space has been actively developed over the past two decades and has been successfully implemented in many industries. One of the first P. Eickhoff performed the theoretical justification of identification, developed algorithms and methods of identification [1,2]. The identification of dynamical systems is devoted to the work of the following authors: D. Gropp [3], L. Ljung [4], E. P. Sage and J. L. Melsa [5, 6],

(C) Yu. R. Nikitin, S. A. Trefilov, 2020 
and among Russian authors - Ya. Z. Tsypkina [7], N. S. Reibman [8], Sh. E. Steinberg [9] and others.

R. Beard developed an observer-based defect detection scheme [10]. Jones continued these studies and developed the Beard-Jones Fault Detection Filter [11]. In the 1980s and early 1990s, the main approaches to quantitative diagnostics were developed: an observer-based approach, a parameter estimation method, etc. Some important works in this direction are Frank [12], Isermann [13], and Basville and Nikiforov [14]. The developed methods are well theoretically justified and are classic diagnostic methods. These techniques are based on analytical redundancy, which is a model that describes the diagnosed technical system. On diagnostics of robot drives, articles and monographs have been published [15-26], where approaches are considered both on the basis of the parametric approach and on the basis of continuous and discrete models of drives in the state space.

\section{RESEARCH PROBLEM STATEMENT}

For robot drives based on a DC motors, which are widely used in robot drives, control equations for continuous nonlinear systems in the state space are given

$$
\begin{gathered}
\dot{\mathbf{x}}=\mathbf{A x}+\mathbf{B u}, \\
\mathbf{y}=\mathbf{C x},
\end{gathered}
$$

where $\mathbf{A}$ is the state matrix, $\mathbf{B}$ is the control matrix, $\mathbf{C}$ is the measurement matrix, $\mathbf{x}$ is the state vector.

The classical model of a DC motor with constant parameters does not correspond to reality in the entire operating range. Therefore, nonlinearity associated with viscous friction was added.

The following differential equations of the first order are known for the robot drives model based on a DC motors:

$$
\begin{gathered}
U=R\left(T \frac{d I}{d t}+I\right)+e, \\
J \frac{d \omega}{d t}=M-k_{f_{r}} \omega-M_{L}, \\
\omega=\frac{d \theta}{d t}, \\
e=k_{E} \omega, \quad M=k_{M} I, \\
T=\frac{L}{R},
\end{gathered}
$$

where $U, I, e$ are the voltage, current and counter-EMF of the DC motor anchor; $L, R, T$ are inductance, resistance and electromagnetic time constant of the anchor DC motor; $\omega, M, M_{L}, \theta$ are angular velocity, electromagnetic moment of the DC motor, the load moment and the angle of a rotation of the DC motor shaft; $J$ is moment of inertia of the rotor DC motor and load; $k_{E}, k_{M}$ are coefficients that are structural constants of the engine; $k_{f r}$ is coefficient of viscous friction of the DC motor.

Further, equation (3) for continuous nonlinear systems is written in the form of Cauchy: 


$$
L \frac{d I}{d t}=-R I-k_{E} \omega+U
$$

To identify the DC motor model, a pair of equations (8) and (4) is used in the state space on the basis of which the vector-matrix model is built. The scalar value, the supply voltage of the drive $U$, is specified as the control vector.

In general terms, when at least one of the matrixes $\mathbf{A}, \mathbf{B}, \mathbf{C}$ are time-dependent, the task is non-linear and has only particular solutions.

To find the equation in the state space, we represent equations $(1,2)$ in a discrete form, and the sampling time $T$ tends to zero, and the trajectory of motion in each discrete section is linear.

We write the solution for the nonlinear problem in a discrete form, when the matrix $\mathbf{A}, \mathbf{B}$, $\mathbf{C}$ are constant at time instants $k, k=0,1,2,3, \ldots$ :

$$
\frac{\mathbf{x}_{k+1}-\mathbf{x}_{k}}{T}=\mathbf{A}_{k} \mathbf{x}_{k}+\mathbf{B}_{k} \mathbf{u}_{k}
$$

or

$$
\mathbf{x}_{k+1}=\tilde{\mathbf{A}}_{k} \mathbf{x}_{k}+\tilde{\mathbf{B}}_{k} \mathbf{u}_{k},
$$

where $\tilde{\mathbf{A}}_{k}=T \mathbf{A}+\mathbf{E}, \tilde{\mathbf{B}}_{k}=T \mathbf{B}_{k}$.

This equation (10) relates the transition of the system from state $\mathbf{x}_{k}$ to state $\mathbf{x}_{k+1}$. On the segment $T$, we take the values of the matrices $\mathbf{A}_{k}, \mathbf{B}_{k}$ and $\mathbf{C}_{k}$ as constants. For convenience, in the following entries we remove the "wavy line" sign.

We assume that the matrix $\mathbf{C}^{-1}=\mathbf{C}_{k}^{-1}$ at each step $k$ does not change, is determined by the information-measuring system, can be represented as

$$
\mathbf{C}^{-1}=\mathbf{E}+\xi_{n},
$$

where $\xi_{n}=\left[\begin{array}{llll}\xi_{1} & \xi_{2} & \ldots & \xi_{n}\end{array}\right]^{\mathrm{T}}$ is a random vector representing the random nature of the measurements by the information-measuring system that is part of the drives.

\section{RoBOT DRIVE MODEL IDENTIFICATION}

Consider the question of identifying the model of robot drives from the point of view of the analysis of expression (10), where at each linearization step the rank of the expanded matrix is the criterion of identifiability and observability.

$$
\min \operatorname{det}\left[\mathbf{C}_{k}^{T} \vdots \mathbf{A}_{k}^{T} \mathbf{C}_{k}^{T}\right] \geq \gamma
$$

where $\mathbf{C}_{k}^{T}$ is the transported measurement matrix, taking into account the accuracy class of the sensors; $\gamma$ is the threshold value of the determinants determined by the identification object and close to zero.

Considering that in many practical control tasks the dimensions of the tasks do not exceed ten, and the relative measurement accuracy is equal to units of percent, we can conclude that only the state matrix affects the identifiability of the robot drive model

$$
\mathbf{A}_{k}^{\mathrm{T}}, k=\overline{1, n} \text {. }
$$


This matrix will ultimately determine the rank of matrix (12). form

It is proposed for practical tasks to determine the identifiability of the drive model in the

$$
\min \operatorname{det} \mathbf{A}_{k}^{\mathrm{T}} \operatorname{det} \mathbf{C}_{k}^{T} \geq \gamma
$$

\section{DiAgNOSTICS OF ROBOT DRIVES BASED ON A DC MOTOR ACCORDING TO THE IDENTIFIABILITY CRITERION OF A DRIVE MODEL}

Consider the diagnosis of drives based on the DC motor in the state space. Since the drive regulator must provide control over the moment and speed of rotation, the armature current $I$ and the armature speed $\omega$ are chosen as generalized coordinates. The control is the voltage at the armature $U$, the disturbance is the load resistance moment $M_{L}$. The model parameters are the active resistance and inductance of the circuit and the armature, denoted respectively by $R$, and $L$, as well as the reduced moment of inertia $J$ and the design constants $k_{E}$ and $k_{M}$. By resolving the original system with respect to the first derivatives, the DC motor equation in the state space is obtained.

We write the vector-matrix model of the DC motor in the form $(1,2)$ in the state space. The novelty of the DC motor model is that the expected torque $M$ is taken into account based on a given trajectory of movement.

$$
\begin{gathered}
\dot{\mathbf{x}}=\left[\begin{array}{c}
\dot{I} \\
\dot{\omega}
\end{array}\right]=\left[\begin{array}{cc}
-\frac{R}{L} & -\frac{k_{E}}{L} \\
\frac{k_{M}}{J} & -\frac{k_{f r} \omega+M}{J \omega}
\end{array}\right]\left[\begin{array}{l}
I \\
\omega
\end{array}\right]+\left[\begin{array}{c}
\frac{1}{L} \\
0
\end{array}\right] \mathbf{u}, \\
\mathbf{y}=\left[\begin{array}{c}
I \\
\omega
\end{array}\right]=\left[\begin{array}{ll}
1 & 0 \\
0 & 1
\end{array}\right] \mathbf{x},
\end{gathered}
$$

We write the vector-matrix model of a DC motor in the form (10).

$$
\begin{gathered}
\mathbf{x}(k+1)=\left[\begin{array}{cc}
1-T \frac{R}{L} & -T \frac{k_{E}}{L} \\
T \frac{k_{M}}{J} & 1-T \frac{k_{f r} \omega+M_{L}(k)}{J \omega(k)}
\end{array}\right] \times\left[\begin{array}{c}
I(k) \\
\omega(k)
\end{array}\right]+\left[\begin{array}{c}
\frac{1}{L} \\
0
\end{array}\right] \mathbf{u}(k), \\
\mathbf{y}(k)=\left[\begin{array}{c}
\hat{I}(k) \\
\hat{\omega}(k)
\end{array}\right]=\left[\begin{array}{cc}
1+h \xi & 0 \\
0 & 1+h \xi
\end{array}\right] \mathbf{x}(k),
\end{gathered}
$$

where $M_{L}(k)=(\omega(k+1)-\hat{\omega}(k)) \frac{J}{T} ; \hat{I}(k), \hat{\omega}(k)$ are measured value of current and angular velocity; $\omega(k+1)$ is the planned value of the angular velocity.

We calculate the load moment in the determinant of matrix $\mathbf{A}$ for equality

$$
\operatorname{det} \mathbf{A}=\left[\begin{array}{cc}
1-T \frac{R}{L} & -T \frac{k_{E}}{L} \\
T \frac{k_{M}}{J} & 1-T \frac{k_{f r_{-} m p} \omega+M_{L}(k)}{J \omega(k)}
\end{array}\right]=0 .
$$


The fact that matrix $\mathbf{A}$ is equal to zero leads (14) to the non-identifiability of the robot drive model in the state space.

The expression $M(k)=(\omega(k+1)-\hat{\omega}(k)) J / T$ gives the relationship between the mechanical parameters of the DC motor, allows you to determine the interval of change of values without loss of identifiability. In addition, restrictions on the maximum rotation speed, electric current, and voltage for this drive must be considered.

\section{COMPUTATIONAL EXPERIMENTS TO STUDY THE IDENTIFIABILITY OF THE DC MOTOR MODEL IN DISCRETE FORM}

The scheme of the DC motor model for calculating the determinant of the state matrix $\mathbf{A}$ was built in the software SimInTech "Environment for Dynamic Modeling of Technical Systems", developed by $3 \mathrm{~V}$ Service ${ }^{1}$.

Figure 1 shows the model for calculating the determinant of the state matrix $\mathbf{A}$ and moment of the DC motor for various values of the armature winding resistance in the case of inter-turn faults in program SimInTech.

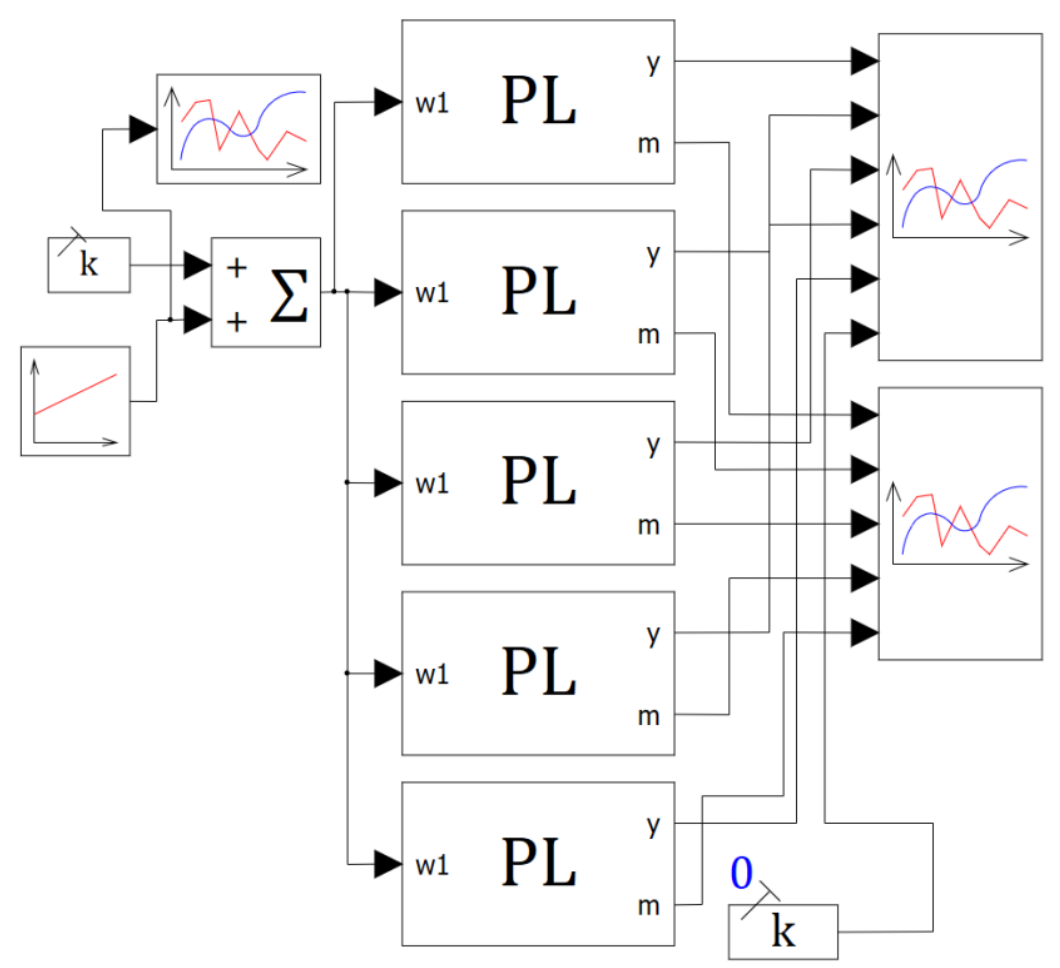

Figure 1. The model for calculating the determinant of the state matrix $\mathbf{A}$ and moment of the DC motor in program SimInTech

The gamma threshold was chosen 0.05 . Figure 2 shows the dependence of the determinant of the state matrix $\mathbf{A}$ on the armature winding resistance $\mathrm{R}$. The influence of changes in the resistance of the armature winding of the DC motor on the determinant of the state matrix A was studied. An analysis of the dependence of the determinant of the state matrix $\mathbf{A}$ on the resistance value of the armature of the DC motor armature shows that the allowable angular velocity decreases from $360 \mathrm{rad} / \mathrm{s}$ to $345 \mathrm{rad} / \mathrm{s}$.

\footnotetext{
${ }^{1}$ Available at: http://simintech.ru/
} 
Yu. R. Nikitin, S. A. Trefilov

"Diagnostics of robot drives based on DC motors by identifiability criterion of nonlinear discrete model in state space"

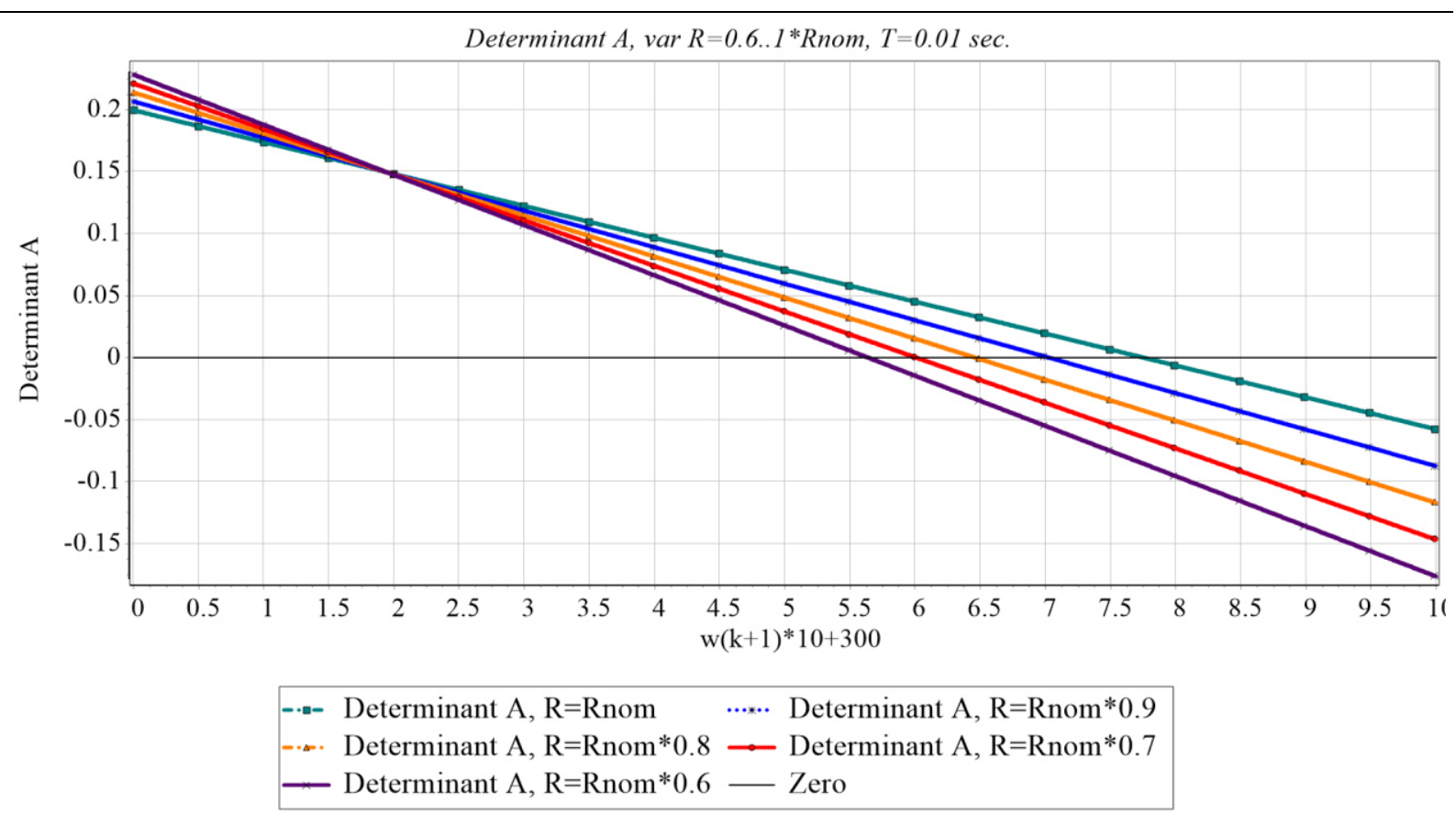

Figure 2. Dependence of the determinant of the state matrix $\mathbf{A}$ on the armature winding resistance $\mathrm{R}$

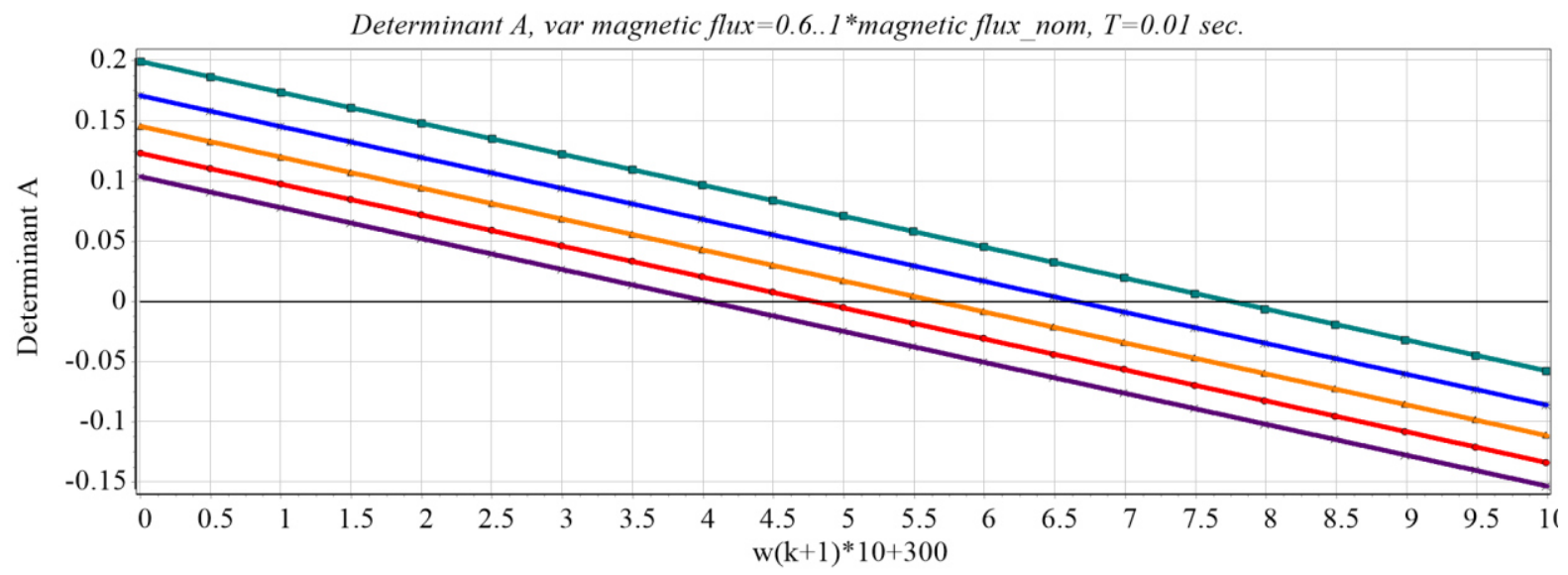

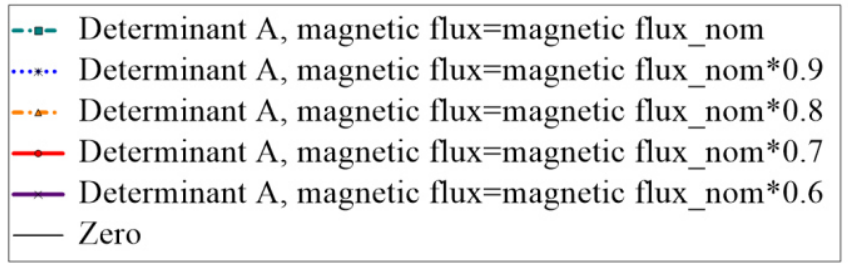

Figure 3. Dependence of the determinant of the state matrix A on the magnetic flux of the DC motor

\section{CONCLUSION}

Figure 3 shows the dependence of the determinant of the state matrix $\mathbf{A}$ on the magnetic flux of the DC motor. An analysis of the dependence of the determinant of the state matrix $\mathbf{A}$ on the magnetic flux of the DC motor shows that the allowable angular velocity decreases from $360 \mathrm{rad} / \mathrm{s}$ to $320 \mathrm{rad} / \mathrm{s}$.

This paper presents an algorithm for identifying nonlinear complex objects based on a discrete digital control model. As a criterion for the optimality of the identification algo- 
rithm, a decision-making criterion is selected in combination with an identifiability criterion for the control algorithm. Identification criteria, allowing either the degree of conformity of the models to the control object using the model of the measuring matrix or the combination of models of the state matrix and measuring matrix. The region of permissible values of angular velocities is obtained depending on the armature winding resistance and the magnetic flux of the DC motor.

The reported study was funded by RFBR according to the research project № 18-08-00772 A.

\section{REFERENCES}

1. Eykhoff, P. (1974). System identification: parameter and state estimation. New York: Wiley-Interscience, $555 \mathrm{pp}$.

2. Eykhoff, P. (Ed.). (1981). Trends and progress in system identification. Oxford, England: Pergamon, 402 pp.

3. Graupe, D. (1976). Identification of system. New York, USA : R.E.Krieger Publishing Company, 302 pp.

4. Ljung, L. (1997). System identification: theory for the user (2nd ed.). Pearson PTG, 640 pp.

5. Sage, A., \& Melsa, J. (1971). System identification. New York, USA : Academic press, $221 \mathrm{pp}$.

6. Sage, A., \& Melsa, J. (1971). Estimation theory with applications to communications and control. New York, USA : McGraw-Hill, 496 pp.

7. Cypkin, Ja. Z. (1984). Osnovy informacionnoj teorii identifikacii [Fundamentals of identification information theory]. Moscow, Russia : Nauka, 320 pp. (in Russian).

8. Rajbman, N. S. (1970). Chto takoe identifikacija? [What is identification?]. Moscow, Russia : Nauka, 118 pp. (in Russian).

9. Shtejnberg, Sh. E. (1987). Identifikacija v sistemah upravlenija [Identification in control systems]. Moscow, Russia : Jenergoatomizdat, 80 pp. (in Russian).

10. Beard, R. V. (1971). Failure accommodation in linear system through selfreorganization (PhD thesis), MIT, USA, $376 \mathrm{pp}$.

11. Jones, H. L. (1973). Failure detection in linear systems (PhD thesis). MIT, USA, 459 pp.

12. Frank, P. M. (1990). Fault diagnosis in dynamic systems using analytical and knowledgebased redundancy: a survey and some new results. Automatica, 26(3), 459-474. doi: 10.1016/0005-1098(90)90018-D.

13. Isermann, R. (2006). Fault-diagnosis systems: an introduction from fault detection to fault tolerance. Berlin; New York : Springer, 475 pp.

14. Basseville, M., \& Nikiforov, I. V. (1993). Detection of abrupt changes: theory and application. Prentice Hall information and system sciences series. Englewood Cliffs, New Jersey, USA : Prentice Hall, 447 pp.

15. Ding, S. X. (2008). Model-based fault diagnosis techniques. Design schemes, algorithms, and tools. Berlin, Heidelberg : Springer, 473 pp. doi: 10.1007/978-3-540-76304-8.

16. Costa, B. S. J. (2016). Fuzzy fault detection and diagnosis. In Handbook on computational intelligence: Vol. 2. Fuzzy logic, systems, artifical neural networks, and learning systems. World Scientific Publishing Co. Pte. Ltd., pp. 251-288. 
17. Luo, H. (2017). Plug-and-play monitoring and performance optimization for industrial automation processes. Springer Vieweg, 158 pp. doi: 10.1007/978-3-658-15928-3.

18. Trefilov, S., \& Nikitin, Y. (2018). Automatic warehouses with transport robots of increased reliability. Acta Logistica, 5(1), 19-23. doi: 10.22306/al.v5i1.86.

19. Zhirabok, A. N., Shumskii, A. E., Solyanik, S. P., \& Suvorov, A. Yu. (2017). Design of nonlinear robust diagnostic observers. Automation and Remote Control, 78(9), 1572-1584. doi: 10.1134/S000511791709003X.

20. Zhirabok, A. N., \& Shumsky, A. E. (2019). Nonparametric method for diagnosis of nonlinear dynamic systems. Automation and Remote Control, 80(2), 217-233. doi: $10.1134 / \mathrm{S} 0005117919020024$.

21. Zhirabok, A. N., Shumsky, A. E., Solyanik, S. P., \& Suvorov, A. Yu. (2017). Design of nonlinear robust diagnostic observers. Automation and Remote Control, 78(9), 1572-1584. doi: 10.1134/S000511791709003X.

22. Stepanov, P. I., Lagutkin, S. V., \& Nikitin, Yu. R. (2013). Kompleksnaja tokovaja i vibrodiagnostika jelektromehanicheskih sistem [Integrated current and vibration diagnostics of electromechanical systems]. Intellektual'nye sistemy $v$ proizvodstve [Intelligent Systems in Manufacturing], (2), 160-165. (in Russian).

23. Stepanov, P. I., Lagutkin, S. V., \& Nikitin, Yu. R. (2014). Mehanicheskie i jelektricheskie diagnosticheskie parametry jelektricheskih privodov [Mechanical and electrical diagnostic parameters of electric drives]. Intellektual'nye sistemy v proizvodstve [Intelligent Systems in Manufacturing], (2), 59-63. (in Russian).

24. Nikitin, Yu. R., Trefilov, S. A., Abramov, A. I., Abramov, I. V., Turygin, Yu. V., \& Romanov, A. V. (2018). Diagnostirovanie privodov mobil'nyh robotov na baze modeli dvigatelya postoyannogo toka [Diagnosing drives of mobile robots based on a DC motor model]. Intellektual'nye sistemy v proizvodstve [Intelligent Systems in Manufacturing], 16(4), 114-121. doi: 10.22213/2410-9304-2018-4-114-121. (in Russian).

25. Nikitin, Yu. R., Trefilov, S. A., \& Nikitin, E. V. (2019). Identifitsiruemost' modeli privoda mekhatronnogo ustroystva na baze dvigatelya postoyannogo toka po izmeritel'noy matritse [Identificability of the mechatronic device drive model on the DC motor basis using measuring matrix]. Fundamental'nye $i$ prikladnye problemy tekhniki $i$ tekhnologii [Fundamental and applied problems of engineering and technology], (4-1), 114-122. (in Russian).

26. Trefilov, S. A., \& Nikitin, Yu. R. (2019). Robot drives diagnostics by identifiability criterion based on state matrix. In Instrumentation Engineering, Electronics and Telecommunications - 2019 : Proceedings of the V International Forum (Izhevsk, Russia, 20-22 Nov., 2019) (pp. 105-114). Izhevsk, Russia: Publishing House of Kalashnikov ISTU. doi: 10.22213/2658-3658-2019-105-114. 